\title{
Does skin thickness affect satisfaction post rhinoplasty?
}

\author{
Middle Eastern population as an example
}

Sami Alharethy, MD, Ahmed Mousa, PhD, Ahmed Alharbi, MD, Turki Aldrees, MBBS, MBA,

Saleh AlQaryan, MBBS, Yong-Ju Jang, $M D P h D$.

\section{ABSTRACT}

$$
\begin{aligned}
& \text { الأهداف : إِن الهدف من هذه الدراسة هو تحديد متوسط سماكة }
\end{aligned}
$$

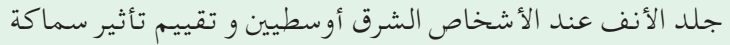

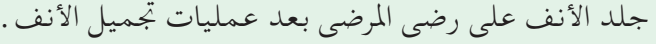

الطريقة : باستخدام الأشعة المقطعية تم قياس سماكة جلد الأنف

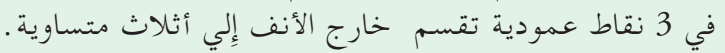

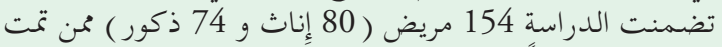

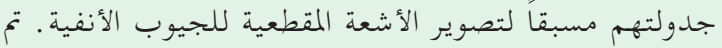

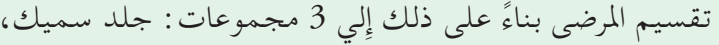

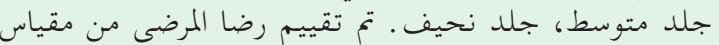

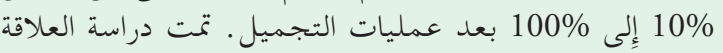

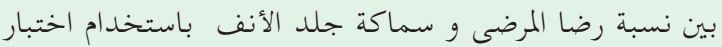

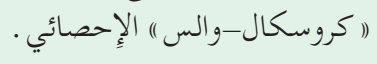

النتائج : سماكة جلد الأنف للذكور كانت 6.13،

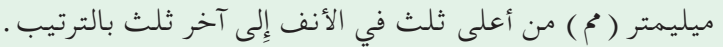

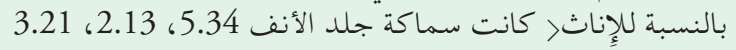

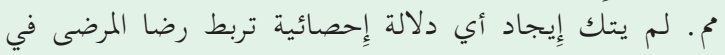
المجموعات الثلاث ( الد لالة الإِحصائية الاحتمالية = 0.089 )

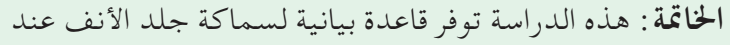

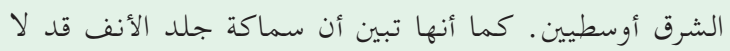

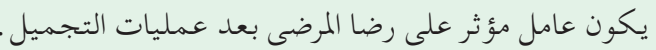

Objectives: To determine the mean nasal skin thickness in the Middle Eastern population and to assess the effect of skin thickness on patients' satisfaction following rhinoplasty surgeries.

Methods: Radiological measurements of skin thickness at the 3 vertical thirds of the nasal dorsum were taken. A total of 154 patients (80 females and 74 males) who were scheduled for computed tomography scan for the paranasal sinuses were included in the study. The patients were then categorized into 3 groups: thick, medium, and thin nasal skin. A scale from $10 \%$ to $100 \%$ was used to assess patient satisfaction following rhinoplasty. Satisfaction and skin thickness were analyzed using the Kruskal-Wallis test.

Results: Nasal skin thickness for males was 6.13, 2.76 millimeter $(\mathrm{mm})$ from the upper and $3.70 \mathrm{~mm}$ to the lower third. For females, it was $5.34,2.13 \mathrm{~mm}$ from the upper and $3.21 \mathrm{~mm}$ to the lower third. There was no statistically significant difference in patient satisfaction among the 3 skin thickness groups $(p=0.089)$.

Conclusion: This study provides baseline results of nasal skin thickness in the Middle Eastern population. The results also show that nasal skin thickness may not be a strong factor affecting patient satisfaction.

Saudi Med J 2018; Vol. 39 (12): 1238-1241

doi: 10.15537/smj.2018.12.23269

From the Department of Otolaryngology-Head and Neck Surgery (Alharethy, AlQaryan), Department of Ophthalmology (Mousa), King Abdulaziz University Hospital, from the Department of Plastic Surgery (Alharbi), King Khalid University Hospital, King Saud University, Riyadh; from the Department of Otolaryngology-Head and Neck Surgery (Aldrees), Prince Sattam bin Abdulaziz University, Al Kharj, Kingdom of Saudi Arabia, and from the Department of Otolaryngology (Jang), Asan Medical Center, University of Ulsan College of Medicine, Seoul, Korea.

Received 1st July 2018. Accepted 31st October 2018.

Address correspondence and reprint request to: Dr. Sami Alharethy, Department of Otolaryngology-Head and Neck Surgery, College of Medicine, King Saud University, Riyadh, Kingdom of Saudi Arabia. E-mail:samiharthi@gmail.com ORCID: 0000-0002-8334-0726

$\mathrm{T}$ he anatomy of the nose and the characteristics of the nose subunits among patients create the basic working ground in facial analysis for predicting rhinoplasty outcomes. Septorhinoplasty is one of the most commonly performed plastic surgery procedures 
in the world. ${ }^{1-4}$ Consequently, it is possible that significant sub-optimal aesthetic problems may arise in these patients because of skin thickness. It is thought that patient with thick nasal skin will have the subtle changes visible and thick-skinned patients require more substantial changes in their nasal framework to achieve dramatic effect on the contour. Moreover, thick-skinned patients require more time postoperatively for the edema to resolve. ${ }^{3}$ Nasal skin thickness varies across races and countries and is different along the entire length of the individual nose. There is a scanty evidence on Middle Eastern nasal skin thickness.

The aim of this study was to develop a standard reference of the thickness of the nasal skin in the Middle Eastern population by means of radiological assessment as well as to assess the effect of skin thickness on patient satisfaction following rhinoplasty.

Methods. Our study included 2 arms: prospectively studying the difference in satisfaction post-rhinoplasty based on skin thickness as an independent factor and descriptively measuring the skin thickness in the Middle Eastern population.

A total of 154 patients (80 females and 74 males) were initially enrolled in the study during the enrollment period (January 2014 - December 2016) at King Abdulaziz University Hospital, Riyadh, Kingdom of Saudi Arabia. The inclusion criteria included patients who previously underwent a computed tomography scan of the paranasal sinuses for functional reasons and those with no history of facial/nasal trauma. We excluded patients with sinus space-occupying lesions, skin diseases, and previous rhinoplasty surgery. Thus, 104 subjects out of 154 underwent rhinoplasty.

All patients had a functional septorhinoplasty through an open approach using infracartilagenous and transcolumellar incisions. Elevation of the skin envelope for septal exposure followed by the creation of symmetrical alar rim strips. Incremental hump reduction with or without spreader grafts. Columellar strut was inserted, and tip sutures with add-on grafts of excised alar cartilage along with bilateral lateral osteotomies were implemented.

For every patient who was selected for rhinoplasty, a data sheet describing the nasal deformities,

Disclosure. This study was funded by the International Scientific Partnership Program (ISPP), King Saud University, Riyadh, Saudi Arabia (ISPP number: 007). measurements, and nasal skin thickness (by digital pinch test) was completed by a senior otolaryngologist dividing the patients clinically into thin, intermediate and thick groups as well as a preoperative visual analog scale patients with major discrepancies in thickness between the 3 parts of the nose were not included. We performed a secondary analysis based on the data we collected, and satisfaction was measured at least one year after the procedure date. For the follow-up, patients were contacted via telephone, and satisfaction with the shape of the postoperative nose was assessed using a self-reported scale from $10 \%$ to $100 \%$ postoperatively. Using CT, the nasal skin thickness was calculated at 3 levels in millimeters in midsagittal views: radix, rhinion, and nasal tip (Figure 1). Attenuation of Hounsfield units range from 190 to 30 was used to identify the fat layer of the nasal skin. Nasal skin thickness was also measured and traced utilizing Housnfield units from the epidermal layer to the fat tissue.

Statistical analysis. The non-parametric KruskalWallis test was used to study the differences in satisfaction between the 3 sub groups: thin, intermediate, and thick nasal skin. A $p$-value of $<0.05$ was considered significant. Descriptive measurement of the mean \pm SD for nasal skin thickness.

Results. In our sample, the mean nasal skin thickness was $6.14 \mathrm{~mm} \pm 1.38$ at the upper third of the nose, $2.76 \mathrm{~mm} \pm 0.67$ at the middle third, and $3.70 \mathrm{~mm} \pm 0.71$ at the nasal tip in male subjects. In females, the mean skin thickness was $5.34 \mathrm{~mm} \pm 1.05$ at the upper third $2.13 \mathrm{~mm} \pm 0.67$ at the middle third, and $3.21 \mathrm{~mm} \pm 0.02$ at the nasal tip (Table 1).

With regard to satisfaction based on skin thickness post-rhinoplasty, out of the 104 patients who were enrolled, 72 patients responded to the satisfaction scale recorded (62\%response rate). Of the 72 respondents, there were 31 males and 41 females, with an overall mean age of 24 years. Moreover, nasal skin thickness among the responders was categorically distributed into 3 groups based on the average of the 3 vertical points mentioned previously: thin $(\mathrm{n}=12,16.6 \%)$, intermediate $(n=33,45.8 \%)$, and thick skin thickness $(\mathrm{n}=27,37.5 \%)$. There was no statistically significant difference between all 3 groups in satisfaction of shape $(p=0.892)$ or airway $(p=0.379)$ post rhinoplasty surgeries. Moreover, turbinate reduction surgery was performed in 30 cases, among which satisfaction with the shape improved significantly from $42.4 \%$ (24.9) to $78.6 \%(16.8) \quad(p<0.0001)$. 
Table 1 - Nasal skin thickness in the upper, middle and lower thirds of the nose based on gender.

\begin{tabular}{lccc}
\hline Gender & Nasion & Rhinion & Tip \\
\hline Male & $6.13 \pm 1.38$ & $2.75 \pm 0.67$ & $3.70 \pm 0.71$ \\
Female & $5.34 \pm 1.06$ & $2.14 \pm 0.68$ & $3.22 \pm 0.93$ \\
\hline
\end{tabular}

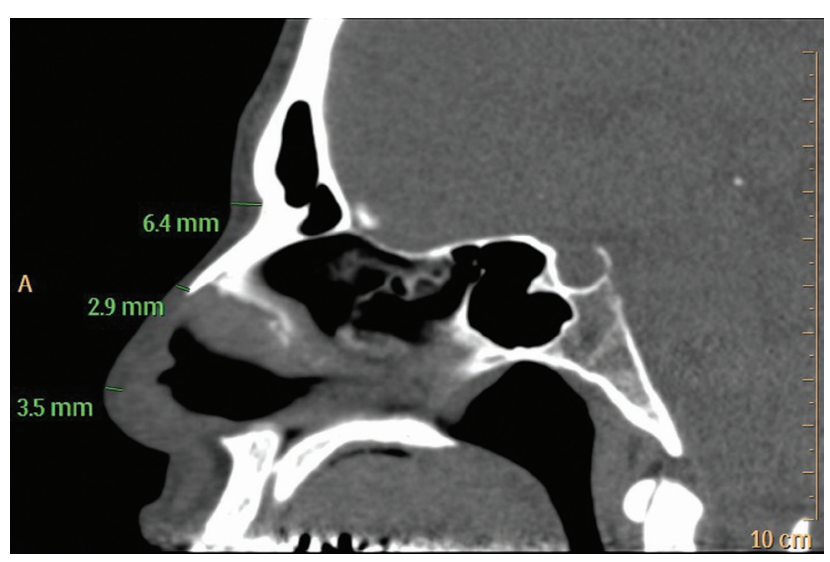

Figure 1 - Radiological nasal skin thickness measured at the nasion, rhinion, and nasal tip at the midline on a sagittal CT.

Discussion. We found that the mean nasal skin thickness at all 3 vertical levels of the nose, namely, the upper third (mean difference of $0.8 \pm 0.33$ ), the middle of the nose $(0.63 \pm 0)$, and the nasal tip $(0.49 \pm 0.69)$, was slightly thicker in males than in females. It was noted that as we went from the upper third to the nasal tip, the margin of difference in skin thickness measurement between males and females markedly decreased. Although the traditional methods of skin thickness measurement rely upon the digital pinch test and photogrammetric analysis, most patients in this study underwent a computed tomography scan for functional nasal purposes, thus enabling us to take an unorthodox approach of measuring skin thickness by imaging as we thought it would provide a more objective mean of measurement. Our measurement of aesthetic satisfaction on a sample of 104 patients was returned with 72 responses, which constitutes a $62 \%$ response rate. Most of the patients were young (mean age 24 years) with a nearly equal gender distribution. As the sample was distributed into 3 groups based on the thickness, our results showed that in terms of satisfaction post-rhinoplasty, there was no difference in satisfaction between patients of varying skin thickness. Moreover, our reasoning behind measuring satisfaction post-rhinoplasty in our sample was 2 -fold. First, it is acknowledged in the literature that surgeons may refrain from performing cosmetic interventions on patients with thick nasal skin due to the susceptibility of prolonged edema, ${ }^{3}$ visible scar formation, ${ }^{5}$ and ultimately suboptimal results. Second, our sample was categorized as having thick skinned noses, based on the mean and standard deviation that was calculated. Hence, our secondary analysis of satisfaction suggests that thick skin may not affect satisfaction and that it is possible to overcome any ethnicity-related nose issue by selecting the appropriate technique and procedure to perform.

The Middle Eastern nose is known to be comprised of over projecting osseo-cartilaginous vault that is covered by thick skin, numerous pilosebaceous units at the tip, dorsal hump, over projected radix, wide upper two-thirds, nasal deviation, long upper lateral cartilages, asymmetric alar cartilages, short medial crura, tip asymmetry, and acute nasolabial angle. ${ }^{5,6}$ Henceforth, our results were in line with the characteristics of the Middle Eastern nose in terms of skin thickness in the literature. In addition, although there are phenotypical differences, the Middle Eastern nose is similar to noses from other ethnicities, such as the African and Mestizo noses, in terms of thick nasal skin thickness; however, there are other anatomical differences. The African nose has a skin thickness of $2-4 \mathrm{~mm}$ just above the lower lateral cartilage with bulbous tip, and the orientation of the lower lateral cartilage is horizontal. ${ }^{7,8}$ The Latino nose or the Mestizo nose also has the inclination of attaining thick skin-soft tissue envelope, yet with a weak bony and cartilaginous structure. ${ }^{9}$ In their trial of understanding the Turks' nose, Özkul et al, 2013 studied the nasal dorsal skin thickness and the right and left alar thickness in a group of Turkish men and women. The mean skin thickness in males over the dorsum was $4.02 \pm 0.71 \mathrm{~mm}$ and $3.38 \pm 0.56 \mathrm{~mm}$ in females. Their results are similar to our results because these values are considered thick, and their findings support that the Middle Eastern nose is inherently thick in nature. ${ }^{10}$ Interestingly, Cho et $\mathrm{al}^{11}$ conducted a comparable study in which they studied the thickness of Korean noses by using CT and measured satisfaction accordingly. Their findings starkly differed from our results from the perspectives of both thickness and satisfaction, suggesting a natural assumption of ethnic differences between the Asian and Middle Eastern nose. In addition, the group that was least satisfied in their sample was the group with the thickest nasal skin, which was contrary to our findings.

Our secondary analysis of satisfaction revealed that there was no difference between the 3 different skin 
thickness groups. There are 2 possible reasons for these results. First, it may be that nasal skin thickness is truly not a factor in determining satisfaction. Second, it may be that post-rhinoplasty satisfaction may be attributed to other demographic and psychosocial characteristics, such as demanding patients, male gender, and some personality disorders. ${ }^{4}$

Study limitations. The results reflect a single-center experience with specific surgical techniques and may not be generalizable. Due to the heterogeneity of the types and degrees of deformities, which may affect the postrhinoplasty satisfaction rate, individualized approach for the determination of the type of rhinoplasty and the specific surgical technique is often warranted.

In conclusion, this study provides baseline results of nasal skin thickness in the Middle Eastern population. This study also shows that nasal skin thickness may not be a strong factor affecting patient satisfaction.

Acknowledgment. The authors extend their appreciation to the International Scientific Partnership Program (ISPP), King Saud University, Riyadh, Saudi Arabia for funding this research work. We would like to thank American Journal Experts (https://www.aje.com) for English language editing.

\section{References}

1. American Society of Plastic Surgeons. 2014 Plastic Surgery Statistics. [cited 2014]. Available from URL: https://www. plasticsurgery.org/news/plastic-surgery-statistics?sub=2014+Pla stic+Surgery+Statistics
2. Klassen AF, Cano SJ, East CA, Baker SB, Badia L, Schwitzer JA, et al. Development and Psychometric Evaluation of the FACE-Q Scales for Patients Undergoing Rhinoplasty. JAMA Facial Plast Surg 2016; 18: 27-35.

3. Rohrich RJ, Ahmad J. A practical approach to rhinoplasty. Plast Reconstr Surg 2016; 137: 725e-746e.

4. Herruer JM, Prins JB, van Heerbeek N, Verhage-Damen GW, Ingels KJ. Negative predictors for satisfaction in patients seeking facial cosmetic surgery: a systematic review. Plast Reconstr Surg 2015; 135: 1596-1605.

5. Apaydin F. Rhinoplasty in the Middle Eastern nose. Facial Plast Surg Clin North Am 2014; 22: 349-355.

6. Sajjadian A. Rhinoplasty in Middle Eastern Patients. Clin Plast Surg 2016; 43: 281-294.

7. Peng GL, Nassif PS. Rhinoplasty in the African American Patient: anatomic considerations and technical pearls. Clin Plast Surg 2016; 43: 255-264.

8. Rohrich RJ, Muzaffar AR. Rhinoplasty in the African-American patient. Plast Reconstr Surg 2003; 111: 1322-1339.

9. Cobo R. Rhinoplasty in Latino Patients. Clin Plast Surg 2016; 43: 237-254.

10. Ozkul MH, Kocagöz DG, Balıkcı HH, Verim A, Yaşar H. A practical method for assessing nasal skin quality. Eur Arch Otorhinolaryngol 2013; 270: 1839-1842.

11. Cho GS, Kim JH, Yeo NK, Kim SH, Jang YJ. Nasal skin thickness measured using computed tomography and its effect on tip surgery outcomes. Otolaryngol Head Neck Surg 2011; 144: 522-527. 